\title{
Variation and Branching Pattern of Profanda Femoris Artery
}

\author{
Jayeeta Chakraborty Moitra ${ }^{{ }^{*}}$, Pooja Sitholay ${ }^{1}$ \\ 1Tutor, Department of Anatomy, \\ Chandulal Chandrakar Memorial Medical College,Kachandur, Durg, Chattisgarh, India.
}

\begin{abstract}
Profunda femoris artery is the largest branch of femoral artery and chief supply of the thigh. It is useful for various clinical procedures like arteriography, ultrasonography and Doppler imaging and haemodialysis. The knowledge of variance in height of origin of profunda femoris artery and its branches has a great significance preventing necrosis of tensor fascia lata flap when used in plastic and reconstructive surgery.

The study was conducted in the Department of Anatomy, Chandulal Chandrakar Memorial Medical College. 33 Femoral triangles were dissected. The distance of the site of origin of Profunda Femoris Artery was measured from mid inguinal point (MIP) with scale, thread, and digital calipers. The sites of origin of Medial Circumflex Femoral Artery and Lateral Circumflex Femoral Artery were also studied and the distances of origin of each of them were measured from the origin of the Profunda Femoris Artery and from the mid inguinal point. The results obtained were tabulated and then statistically analysed using chi square test but significant result was obtained only in case of comparison of the distances of origin of MCFA from MIP with the distance of origin of PFA from MIP $(p<0.05)$.

The knowledge of the side of origin of the Profunda Femoris
\end{abstract}

\section{INTRODUCTION}

Profunda femoris artery is the largest branch of femoral artery and chief supply of the thigh. It is useful for various clinical procedures like arteriography, ultrasonography and Doppler imaging and haemodialysis. Hence, accurate anatomical knowledge is very important for the clinicians. Variation in pattern of femoral artery (FA) and its branches are clinically very important. Hence it has received attention from various anatomists and surgeons. Also accurate knowledge of anatomical variations regarding origins of the profunda femoris, medial and lateral femoral circumflex femoral arteries are important for clinicians in the present mordern era of interventional radiology. ${ }^{1-3}$

The profunda femoris artery (PFA) is the largest branch of the femoral artery. This vessel is useful for the doppler imaging, ultrasound, arteriography, angiography and also magnetic resonance imaging (MRI). ${ }^{1,4}$ The profunda femoris artery usually arises from the posterolateral aspect of the femoral artery. The medial and lateral circumflex femoral arteries normally arise from the profunda femoris artery near to its origin. ${ }^{1,3,5}$

Before going to discuss the study, it is essential to elaborate the anatomy of femoral artery and its branches. Femoral artery is the continuation of the external iliac artery that enters the femoral triangle behind the inguinal ligament midway between the anterior superior iliac spine (ASIS) and symphysis pubis (mid inguinal point). The artery passes downward and medially and leaves the femoral triangle through its apex beneath the sartorius.
Artery helps in avoiding iatrogenic femoral arterio-venous fistula while performing femoral artery puncture \& it enable to identity the correct site of making incision for surgical exposure of the common femoral and profunda femoris junction.

Key words: Mid inguinal point, Medial circumflex femoral artery, Profunda femoris artery.

*Correspondence to:
Jayeeta Chakraborty Moitra, Tutor, Department of Anatomy,
Chandulal Chandrakar Memorial Medical College, Kachandur,
Durg, Chattisgarh, India.
Article History:
\begin{tabular}{|l|c|} 
Received: 06-02-2016, Revised: & 12-02-2016, Accepted: 28-04-2016 \\
\hline \multicolumn{2}{|c|}{ Access this article online } \\
\hline $\begin{array}{l}\text { Website: } \\
\text { www.jimrp.com }\end{array}$ \\
\hline $\begin{array}{l}\text { Dol: } \\
\text { 10.21276/ijmrp.2016.2.3.051 }\end{array}$
\end{tabular}

It traverses the adductor canal and finally appears in the popliteal fossa after passing through the fifth osseo-aponeurotic opening of adductor magnus. The proximal 3 to $4 \mathrm{~cm}$ of the artery along with femoral vein enclosed in femoral sheath.

Relations of Profunda femoris artery in the femoral triangle:

1. Anterior relations

- Skin, superficial fascia, superficial inguinal lymph nodes, superficial circumflex iliac vein.

- Fascia lata, femoral sheath, femoral branch of genito-femoral nerve before piercing the femoral sheath.

- Crossed by medial femoral cutaneous nerve from lateral to medial side, close to apex of the triangle.

2. Posterior relations

- Proximo-distally, the artery rests on psoas tendon, pectineus and adductor longus.

- Psoas tendon intervenes between the artery and the capsule of the hip joint, the artery is separated from the psoas by the femoral sheath and the nerve to the pectineus.

- Separated from the pectineus by the profunda femoris vessels.

- Separated from the adductor longus by femoral vein.

3. Medial relations

- Femoral vein lies medial to the artery in the upper part and behind the artery in the lower part.

- In the upper part lies the trunk of femoral nerve, outside the femoral sheath. 
Medial femoral cutaneous nerve and saphenous nerve, branches of the femoral nerve, accompany on lateral side of the artery in the lower part. Medial cutaneous nerve crosses in front of the artery at the apex of the femoral triangle, and the saphenous nerve crosses in front of the artery from lateral to medial side in the middle of the adductor canal.

Profunda Femoris Artery is the largest branch of femoral artery. It provides the principal supply of the extensor, adductor and flexor group of muscles of thigh. It arises from the lateral side of the femoral artery (may arise posterolateral also) about $3.5 \mathrm{~cm}$ below the inguinal ligament and spirals medially behind the femoral vessels. The artery leaves the femoral triangle between pectineus and adductor longus and descends successively between adductor longus and adductor brevis, then between adductor longus and adductor magnus. Finally it pierces the adductor magnus as the fourth perforating artery and anastomoses with the superior muscular branches of popliteal artery. In the femoral triangle the Profunda Femoris Artery gives off lateral and medial circumflex arteries.

During rest of the course it provides muscular branches and three perforating arteries.

(a) Lateral circumflex femoral artery (LCFA): It passes laterally between the anterior and posterior division of femoral nerve, and disappears from the femoral triangle beneath the sartorius and rectus femoris. Here it divides into ascending, descending and transverse branches.

(b) Medial circumflex femoral artery (MCFA): It winds round the medial side of femoral shaft and passes successively between the psoas and pectineus, adductor brevis and obturator externus, quadratus femoris and upper border of the adductor magnus. It divides mainly into transverse and ascending branches.

(c) Perforating arteries: These are four in numbers, the last one being the continuation of Profunda Femoris Artery. The perforating arteries pierce the adductor magnus and lateral intermuscular septum, supply the adductor and hamstring muscles and end in vastus lateralis muscle where they are connected to one another by a series of anastomoses. The first perforating artery lies above the adductor brevis, the second in front of the brevis and the third lies immediately below it and also gives nutrient artery of femur.

The above mentioned arteries have much implication in clinical practice. The branches of the Lateral Circumflex Femoral Artery are used in anterolateral thigh flap, $, 5,6$ aortopopliteal bypass, 7,8 coronary artery bypass grafting (CABG), ${ }^{9}$ an extracranialintracranial (EC-IC) bypass surgery. ${ }^{10}$ The descending branch of the artery can act as a collateral. ${ }^{11}$ The ascending branch of the artery can be used as a supply for vascularised iliac transplantation. ${ }^{12}$ So, the knowledge of variance in height of origin of profunda femoris artery and its branches has a great significance preventing necrosis of tensor fascia lata flap when used in plastic and reconstructive surgery. ${ }^{13-15}$

\section{MATERIALS AND METHODS}

The study was carried out in the Department of Anatomy in Chandulal Chandrakar Memorial Medical College (CCMMC). 33 Femoral triangles were dissected on fine cadavers used for teaching undergraduate students from 2013 to 2015.

\section{Procedure}

The incision was given in the skin, which was reflected to clean the superficial fascia. The superficial inguinal lymph nodes, superficial lymph vessels and nerves were dissected by fine dissection. The fascia lata was incised and femoral triangles were exposed. The contents of femoral triangle including the branches of profunda femoris artery were identified. The profunda femoris vessel and its medial and lateral circumflex arteries were dissected and identified. Damaged femoral arteries, Profunda Femoral Artery and its branches were excluded in this procedure. Only the properly preserved and intact vessels were considered for this study purposes.

The distance of the site of origin of Profunda Femoris Artery was measured from mid inguinal point (MIP) which is the midpoint between the anterior superior iliac spine and the pubic tubercle in centimeters with scale, thread, and digital calipers. The sites of origin of Medial Circumflex Femoral Artery and Lateral Circumflex Femoral Artery were also studied and the distances of origin of each of them were measured from the origin of the Profunda Femoris Artery and from the mid inguinal point. After that, the artery was coloured with red, vein with blue, nerve with yellow and Mid Inguinal Point with green and then photographs were taken. The collected datas were recorded and analysed. The $p$ value $<0.05$ was considered statistically significant.

Table 1: Comparison between the distance of origin of PFA from mid inguinal point on both side.

\begin{tabular}{|c|c|c|c|c|c|}
\hline Side of & Distance of or & f PFA from & uinal point(M & & $X^{2}$, df \& P \\
\hline Artery & Less than $3 \mathrm{~cm}$ & 3 to $4 \mathrm{~cm}$ & Above $4 \mathrm{~cm}$ & Total & \\
\hline Left & 5 & 19 & 9 & 33 & $X^{2}=1.198$ \\
\hline Right & 5 & 15 & 13 & 33 & $d f=2$ \\
\hline Total & 10 & 34 & 22 & 66 & $P=0.549$ \\
\hline
\end{tabular}

Where $\mathrm{X}^{2}=$ chi-square test, $\mathrm{df}=$ degree of freedom, $\mathrm{P}=$ probability, $\mathrm{PFA}=$ profunda femoris artery.

Table 2: Comparison between the distance of origin of LCFA from the origin of PFA on both side.

\begin{tabular}{lcrccc}
\hline Side of & \multicolumn{3}{c}{ Distance of origin of LCFA from the origin 0f PFA } & & X', df \& P \\
\cline { 2 - 5 } Artery & Less than $\mathbf{2} \mathbf{~ c m}$ & $\mathbf{2}$ to $\mathbf{3} \mathbf{~}$ & Above $\mathbf{3} \mathbf{~ c m}$ & Total & \\
Left & 10 & 14 & 9 & 33 & $\mathrm{X}^{2}=0.571$ \\
Right & 8 & 17 & 8 & 33 & $\mathrm{df}=2$ \\
Total & 18 & 31 & 17 & 66 & $\mathrm{P}=0.751$ \\
\hline
\end{tabular}

(Where: LCFA=lateral circumflex femoral artery) 
Table 3: Comparison between the distance of origin of MCFA from the origin of PFA on both side.

\begin{tabular}{|c|c|c|c|c|c|}
\hline \multirow[t]{2}{*}{ Side of Artery } & \multicolumn{3}{|c|}{ Distance of origin of MCFA from the origin of PFA } & & \multirow[t]{2}{*}{$X^{2}, \mathrm{df} \& \mathrm{P}$} \\
\hline & Less than $2 \mathrm{~cm}$ & 2 to $3 \mathrm{~cm}$ & Above $3 \mathrm{~cm}$ & Total & \\
\hline Left & 4 & 10 & 19 & 33 & $X^{2}=0.190$ \\
\hline Right & 3 & 11 & 19 & 33 & $d f=2$ \\
\hline Total & 7 & 21 & 38 & 66 & $P=0.909$ \\
\hline
\end{tabular}

(Where: MCFA=medial circumflex femoral artery)

Table 4: Comparison between the distances of origin of MCFA from the mid inguinal point (MIP) on both sides.

\begin{tabular}{|c|c|c|c|c|c|}
\hline \multirow{2}{*}{$\begin{array}{l}\text { Side of } \\
\text { Artery }\end{array}$} & \multicolumn{3}{|c|}{ Distance of origin of MCFA from the origin of MIP } & \multirow[b]{2}{*}{ Total } & \multirow[t]{2}{*}{$X^{2}$, df \& P } \\
\hline & Less than $4 \mathrm{~cm}$ & 4 to $6 \mathrm{~cm}$ & Above $6 \mathrm{~cm}$ & & \\
\hline Left & 5 & 21 & 7 & 33 & $X^{2}=0.091$ \\
\hline Right & 5 & 20 & 8 & 33 & $d f=2$ \\
\hline Total & 10 & 41 & 15 & 66 & $\mathrm{P}=0.955$ \\
\hline
\end{tabular}

Table 5: Comparison between the distances of origin of LCFA from the MIP on both sides.

\begin{tabular}{lccccc}
\hline Side of & \multicolumn{3}{c}{ Distance of origin of LCFA from the MIP } & X',df \& P \\
\cline { 2 - 5 } Artery & Less than $\mathbf{4} \mathbf{~ c m}$ & $\mathbf{4}$ to $6 \mathbf{c m}$ & Above $\mathbf{~ c m}$ & Total & \\
Left & 6 & 18 & 9 & 33 & $\mathrm{X}^{2}=0.144$ \\
Right & 5 & 18 & 10 & 33 & $\mathrm{df}=2$ \\
Total & 11 & 36 & 19 & 66 & $\mathrm{P}=0.931$ \\
\hline
\end{tabular}

Table 6: Comparison between the distances of origin of MCFA from MIP with the distance of origin of PFA from MIP.

\begin{tabular}{|c|c|c|c|c|c|}
\hline \multirow{2}{*}{$\begin{array}{l}\text { Distance of origin } \\
\text { of PFA from MIP }\end{array}$} & \multicolumn{3}{|c|}{ Distance of origin of MCFA from MIP } & \multirow[b]{2}{*}{ Total } & \multirow[t]{2}{*}{$\mathrm{X}^{2}$, df \& P } \\
\hline & $\begin{array}{c}\text { Less than } 4 \\
\mathrm{~cm}\end{array}$ & 4 to $6 \mathrm{~cm}$ & Above $6 \mathrm{~cm}$ & & \\
\hline Less than $3 \mathrm{~cm}$ & 0 & 8 & 2 & 10 & $X^{2}=13.289$ \\
\hline 3 to $4 \mathrm{~cm}$ & 6 & 25 & 3 & 34 & $d f=4$ \\
\hline Above $4 \mathrm{~cm}$ & 4 & 8 & 10 & 22 & $\mathrm{P}=0.010$ \\
\hline Total & 10 & 41 & 15 & 66 & \\
\hline
\end{tabular}

This comparison is statistically significant (because $\mathrm{P}$ Value=less than 0.[05)

Table 7: Comparison between the distances of origin of LCFA from MIP with the distance of origin of PFA from MIP.

\begin{tabular}{|c|c|c|c|c|c|}
\hline \multirow{2}{*}{$\begin{array}{l}\text { Distance of origin } \\
\text { of PFA from MIP }\end{array}$} & \multicolumn{3}{|c|}{ Distance of origin of LCFA from MIP } & \multirow[b]{2}{*}{ Total } & \multirow[t]{2}{*}{$\mathrm{X}^{2}, \mathrm{df} \& \mathrm{P}$} \\
\hline & Less than $4 \mathrm{~cm}$ & 4 to $6 \mathrm{~cm}$ & Above $6 \mathrm{~cm}$ & & \\
\hline Less than $3 \mathrm{~cm}$ & 4 & 4 & 2 & 10 & $X^{2}=6.478$ \\
\hline 3 to $4 \mathrm{~cm}$ & 6 & 19 & 9 & 34 & $d f=4$ \\
\hline Above $4 \mathrm{~cm}$ & 1 & 13 & 8 & 22 & $P=0.166$ \\
\hline Total & 11 & 36 & 19 & 66 & \\
\hline
\end{tabular}

\section{RESULTS \& DISCUSSION}

In the present study, the profunda femoris artery originated from the posterior side of the common femoral artery $(16 / 66,25 \%)$. Twenty six percent of this artery (17/66) originated from posterolateral side of the femoral artery. The two sides of origin have been described in the anatomy texts as the sides of origin of the artery. ${ }^{1,16}$ However, in this study 33 out of 66 arteries (50\%) originated from the lateral aspect of the common femoral artery (Fig 1 and 2). M B Samarawickrama et al also showed in their study $23 \%$ Profunda Femoris Artery originated from the lateral aspect. Table 1 showed the origin of Profunda Femoris Artery from the mid inguinal point as the normal $(3-4 \mathrm{~cm})$, but also It was found around in $40 \%$, originated close to the mid inguinal point (MIP). There were no significant variations found. But M B Samarawickrama et al showed an interesting feature that, when the artery originated close to the inguinal ligament (shorter the distance of origin), then it was from the lateral side of the common femoral artery. The knowledge of the side of origin of the Profunda Femoris Artery helps in avoiding iatrogenic femoral arterio-venous fistula while performing femoral artery puncture \& it enable to identity the correct site of making incision for surgical exposure of the common femoral and profunda femoris junction.

The lateral circumflex femoral artery (LCFA) mostly originated from the profunda femoris artery (PFA) and it was accurately cent percent in this study, which has been shown in Fig 3. That was the commonest pattern of origin of this artery sited in the literature. ${ }^{1,17-19}$ Present study did not encounter any artery, which originated from the common femoral artery that already has been shown in table 2. 


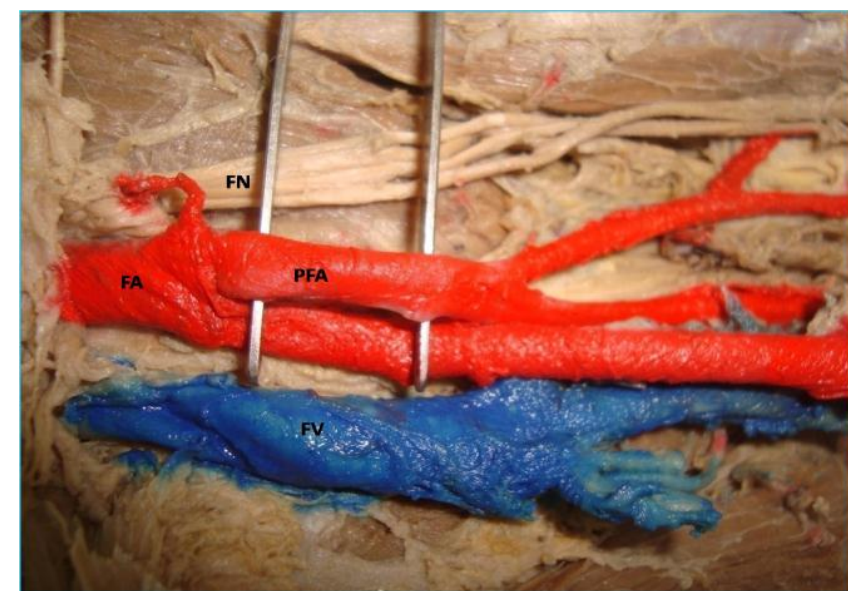

Fig 1: Origin of Profunda Femoris Artery from the Common Femoral Artery. (FN= Femoral Nerve, PFA= Profunda Femoris Artery, $F A=$ Femoral Artery, FV= Femoral Vein)

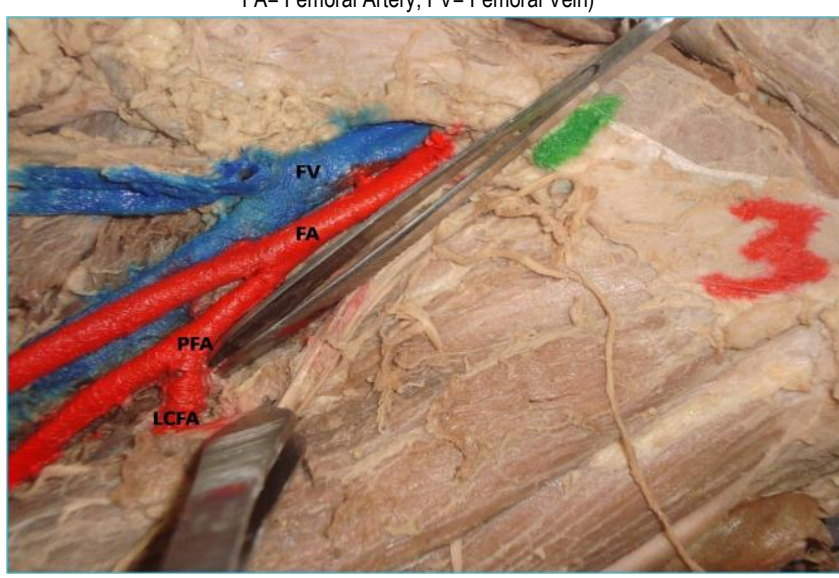

Fig 3: Origin of the lateral circumflex femoral artery (LCFA) from the Profunda femoris artery [Green colour = mid inguinal point (MIP)] ( $F V=$ Femoral Vein, PFA= Profunda Femoris Artery, FV= Femoral Vein LCFA $=$ Lateral Circumflex Femoral Artery)

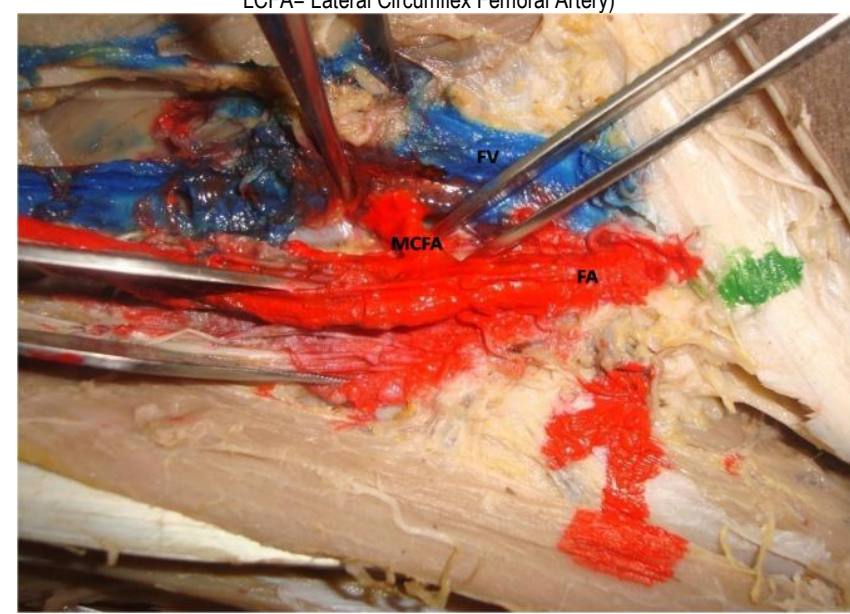

Fig 5: MCFA directly originated from the Common Femoral Artery.

(FV= Femoral Vein, FA= Femoral Artery, MCFA= Medial Circumflex Femoral Artery)

On contrast with this, Table 6 also has shown the distance of Lateral Circumflex Femoral Artery from Mid Inguinal Point, where this study did not show any significant variation. But the study of $M$ Uzel et al ${ }^{5}$ showed that Lateral Circumflex Femoral Artery directly originated from the main femoral artery.

The medial circumflex femoral artery (MCFA) on an average originated from the Profunda Femoris Artery. In the present study, $91 \%$ cases originated from the profunda femoris, but in $7 \%$ cases, 3 out of 33 (Fig 5), medial circumflex femoral arteries found to be originated from the main common femoral artery. This was comparable to some other studies where most of the time the

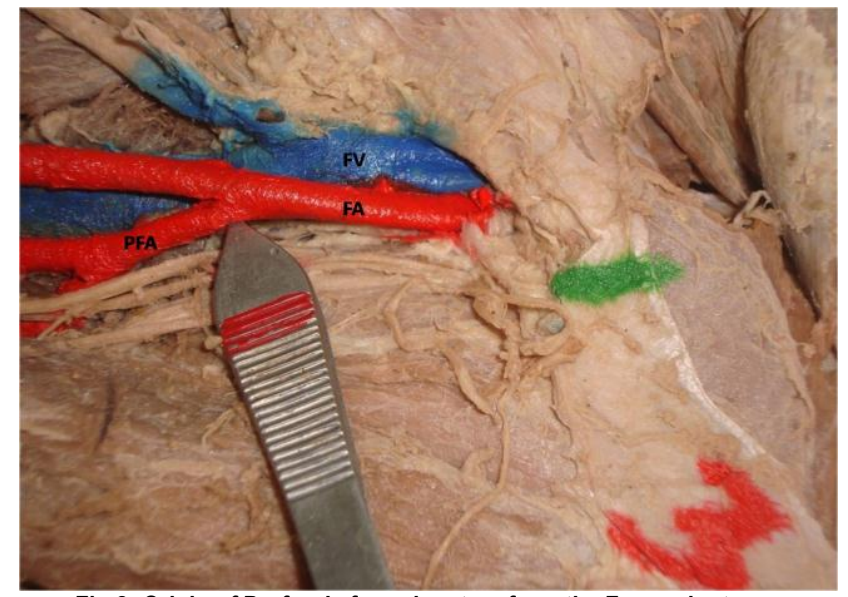

Fig 2: Origin of Profunda femoris artery from the Femoral artery. (FV= Femoral Vein, PFA= Profunda Femoris Artery,

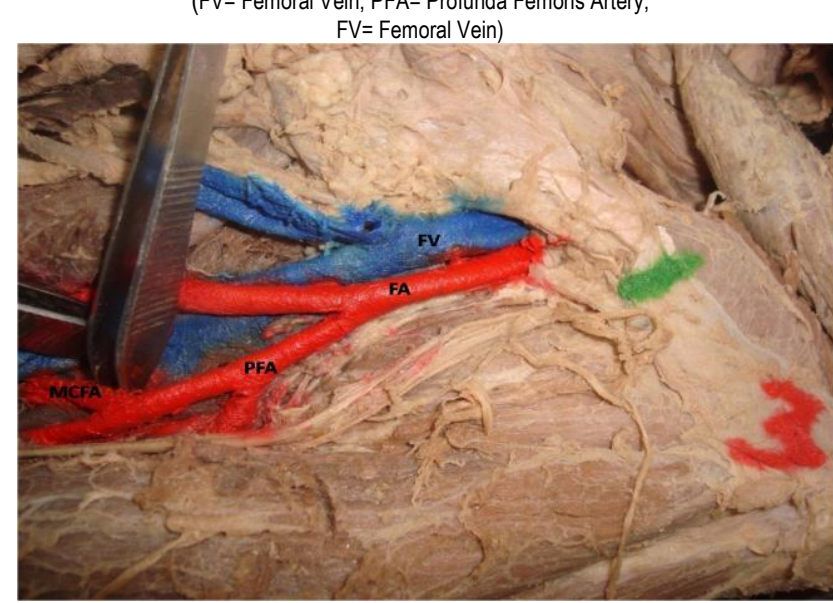

Fig 4: Origin of the Medial circumflex femoral artery (MCFA) from the Profunda femoris artery.

( $F V=$ Femoral Vein, PFA= Profunda Femoris Artery, FA= Femoral Artery, MCFA= Medial Circumflex Femoral Artery)

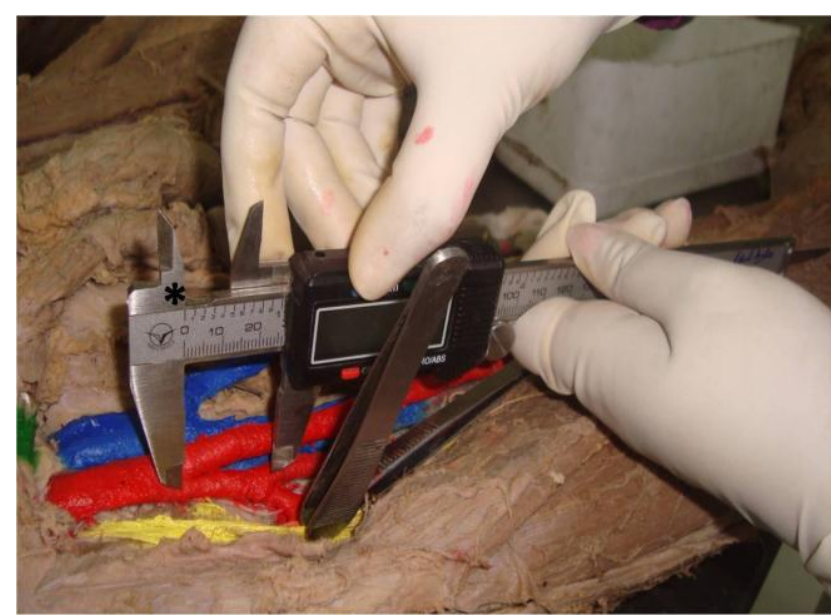

Fig 6: Measurement of distances by digital caliper.

Medial Circumflex Femoral Artery originated from Profunda Femoris Artery. ${ }^{1,5}$

The origin of Medial Circumflex Femoral Artery placed very close to the root of the Profunda Femoris Artery (Fig 4), was comparable to the classical text book description. ${ }^{1,16}$ In table 3 the study had shown that artery originated above $3 \mathrm{~cm}$ from the root of the profunda femoris in $58 \%$ cases on both side and there was no significant difference (showed in table 5).

The table 6, has shown the comparison of the distance of Medial Circumflex Femoral Artery from Mid Inguinal Point with the distance of origin of Profunda Femoris Artery from Mid Inguinal 
Point. There, was a significant difference $(P$ value $=0.010)$ seen between those two parameters.

But, in case of Lateral Circumflex Femoral Artery, there was no significant difference (table 7). Whereas, when it was compared between the distance of Lateral Circumflex Femoral Artery with the position of Profunda Femoris Artery

Some, studies showed that the Medial Circumflex Femoral Artery and Lateral Circumflex Femoral Artery by origin and relation wise they may vary.1,2,5.20 It has many clinical implications in clinical practice.

\section{REFERENCES}

1. M B Samarawickrama, B G Nanayakkara. Branching pattern of the femoral artery at femoral triangle: a cadaveric study. Galle Medical Journal. 2009,14:1.

2. M Bapist, F Sultana, T Hussain. Anatomical Variations: The origin of profunda femoris artery, its branches and diameter of the femoral artery. Professional Medical Journal. 2007; 14:3.

3. A Vuksanovic-Bozaric. Analysis of deep femoral artery origin variences of fetal material. Journal of Medicine and Biology. Vol. 14, Nov 32007.

4. Song R, Gao Y, Song Y, Yu Y, Song Y. The forearm flap. Clin Plast Surg 1982;9: 21-6.

5. M Uzel, E Tanyeli, M Yildirim. An anatomical study of the origins of the Lateral circumflex femoral artery in the Turkish population. Folia Morphol. 2008;67:4.

6. Valdatta L, Tuinder S, Buoro M, Thione A, Faga A, Putz R (2002) Lateral circumflex femoral arterial system and perforators of the anterolateral thigh flap: an anatomic study. Ann Plast Surg, 49: 145150.

7. Gradman WS (1992) Bypass to the lateral circumflex femoral artery. Ann Vasc Surg, 6: 344-346.

8. Sugawara $Y$, Sato $O$, Miyata $T$, Kimura $H$, Namba T, Makuuchi M (1998) Utilization of the lateral circumflex femoral artery as a midway outflow for aortopopliteal midway outflow for aortopopliteal grafting: report of a case. Surg Today, 28: 967-970.

9. Fukuda H, Ashida M, Ishii R, Abe S, Ibukuro (2005) Anatomical variants of the lateral femoral circumflex artery: an angiographic study. Surg Radiol Anat, 27: 260-264.

10. Başkaya MK, Kiehn MW, Ahmed AS, Ateş Ö, Niemann DB (2008) Alternative vascular graft for extracranial-intracranial bypass surgery: descending branch of the lateral circumflex femoral artery. Neurosurg Focus, 24: 1-7.

11. Hage JJ, Woerdeman LA (2004) Lower limb necrosis after use of the anterolateral thigh free flap: is preoperative angiography indicated? Ann Plast Surg, 52: 315-318.
12. Xu DC, Kong JM, Zhong SZ (1989) The ascending branch of the lateral circumflex femoral artery. A new supply for vascularized iliac transplantation. Surg Radiol Anat, 11: 263-264.

13. Valdatta L, Tuinder S, Buoro M, Thione A: Lateral Circumflex Femoral Arterial System and Perforators of the Anterolateral Thigh Flap: An Anatomic Study. Annals of Plastic Surgery August 2002;49(2):145-150.

14. Yazici B: Use of conjunctiva-Müller muscle pedicle flap in surgical treatment of necrotizing scleritis. Ophthal Plast Reconstr Surg. 2008 Jan-Feb;24(1):19- 23.

15. Bilgic $S$, Sahin B. Rare arterial variation: a common trunk from the external iliac artery for the obturator, inferior epigastric and profunda femoris arteries. Surg Radiol Anat 1997; 19: 45-47.

16. GJ Romanes. Upper and Lower limbs. Cunningham's Manual of Practical Anatomy. Vol 1, 15 ed. Oxford University Press, 1987; pp 141. E Tanyeli, M Uzel, MYildirim, HH Celik. An anatomical study of the origins of the medial circumflex femoral artery in the Turkish population. PMID:12557421 [PubMed - indexed for MEDLINE].

17. DP Dixit, LAMehta, MLKothari. Variations in the Origin and Course of Profunda Femoris. Journal of the Anatomical Society of India 2001; 50(1): 6-7.

18. MT Vazquez, J Murillo, E Maranillo, I Parkin, J Sanudo. Patterns of the circumflex femoral arteries revisited. PMID: 16617441 [PubMed - indexed for MEDLINE].

19. Kumari PJ. Bharswad AK, JoseBA, Yadav SK, Singh G. Variations in the origins of the profunda femoris, medial and lateral femoral circumflex arteries: a cadaver study in the Indian population. Romanian Journal of Morphology and Embryology 2010, 51(1):167170.

20. Tanvaa Tansatit MD, Samang Wanidchaphloi MSc. The anatomy of the lateral circumflex femoral artery in anterolateral thigh flap. $J$ Med Assoc Thai. 2008; 91: 9.

\section{Source of Support: Nil. Conflict of Interest: None Declared.}

Copyright: () the author(s) and publisher. IJMRP is an official publication of Ibn Sina Academy of Medieval Medicine \& Sciences, registered in 2001 under Indian Trusts Act, 1882.

This is an open access article distributed under the terms of the Creative Commons Attribution Non-commercial License, which permits unrestricted non-commercial use, distribution, and reproduction in any medium, provided the original work is properly cited.

Cite this article as: Jayeeta Chakraborty Moitra, Pooja Sitholay. Variation and Branching Pattern of Profanda Femoris Artery. Int J Med Res Prof. 2016; 2(3):233-37. 